\title{
MOÇAMBIQUE GEODIVERSO: POR UMA GEOGRAFIA INCLUSIVA NO ENSINO E NA
}

PESQUISA

\author{
Mozambique Geodiverse": For an Inclusive Geography in Education and Research \\ Prof. Dr. Zacarias Alexandre Ombe ${ }^{1}$ \\ Professor do Colégio de Doutorado em Geografia da Universidade Pedagógica de Moçambique \\ zombe@up.ac.mz
}

Artigo recebido em 09/03/2014 e aceito para publicação em 24/06/2014

DOI: 10.12957/tamoios.2014.9923

RESUMO Nesta comunicação advoga-se a necessidade de introduzir e promover o paradigma da diversidade em Moçambique pelo seu potencial em ser resposta adequada ao atual cenário reducionista, por contrapor-se através de uma abordagem que, ao estudar territórios e grupos humanos, aprecie a riqueza de nuances das contribuições particulares para escalas cada vez mais alargadas. Como forma de operacionalização do paradigma, com base em pesquisas bibliográficas e de campo, propõe-se o emprego, na caracterização dos espaços geográficos, dos conceitos de Geodiversidade, Biodiversidade e Sociodiversidade, assim como a melhoria na caracterização da geografia tradicional nos manuais de ensino. Importa constata que os dois primeiros conceitos já estão em uso nos círculos acadêmicos ligados à conservação, mas possui ainda uma circulação restrita entre os geógrafos.

Palavras-chave: África, Moçambique, Paradigma da Diversidade, Inclusão no Ensino da Geografia e Agricultura Tradicional.

ABSTRACT This communication advocates the need to introduce and systematically promote the paradigm of diversity in Mozambique for its revitalizing potential on the relevance of geography in coping with contemporary problems. The paradigm of diversity and inclusion can be an appropriate response to the current reductionism scenario, through an approach that, when studying human groups and territories enjoy the richness of nuances of private contributions to increasingly extended ranges. As a mean of operationalization of the paradigm, based on bibliographic and field research, in the characterisation of geographic spaces, the concepts of Geodiversity, Biodiversity and Sociodiversity, as well as improved characterisation of traditional agriculture in the teaching of geography were suggested. It is important to note that the first two concepts are already in use in academic circles linked to conservation but the last also has a restricted circulation among geographers. Its introduction is due to its structural similarity with the others.

Keywords: Africa, Mozambique, paradigm of diversity, inclusion in the teaching of geography and traditional/subsistence agriculture. 


\section{INTRODUÇÃO}

O estudo das ciências geográficas atravessa um período fértil quanto ao contexto econômico, político e social que encomenda a intervenção da geografia como ciência das relações entre a sociedade e o ambiente natural que, já não estando definitivamente no seu estado original, reflete cada vez mais a ação acumulada da sociedade humana sobre as suas características e dinâmicas. A crise económica que se vive na atualidade e os debates em torno da funcionalidade da integração revelam a fraqueza da globalização no seu processo de uniformização e homogeneização e de sua capacidade em globalizar o bem-estar, apesar do seu poder de permanentemente modernizar as comunicações.

A crise associada a uma maior frequência de fenómenos naturais extremos atua a favor da chamada de atenção para a relevância da Geografia, reforçando a convicção de que os recursos, as condições naturais particulares e as histórias ambientais diversas de cada país, região e lugar são determinantes na avaliação dos benefícios da modernização e da globalização tecnológica, política, económica e cultural.

Moçambique é um país em transição, onde o passado é a referência mais segura do que o presente. O futuro está cheio de interrogações devido à rapidez com que a globalização desestrutura e reestrutura os padrões de uso da terra. Na escala local das regiões rurais, onde as pessoas dependem dos recursos locais para a sua subsistência, é que se sofre maior exclusão na pesquisa e no ensino. Moçambique é ainda um país pós-colonial, pós-economia centralizada e pós-conflito. Cada uma das sequelas mencionadas faz-se sentir de maneira diferenciada nos diversos espaços nacionais. Esta diversidade de configurações sócio-ambientais reflete-se nas condições de vida das pessoas e no grau de preparação que elas possuem para receber os estímulos dos investimentos exteriores e tirar partido dos investimentos globalizantes.

\section{O PARADIGMA DA DIVERSIDADE}

Assim, o paradigma da diversidade em Geografia, para Moçambique, resulta da constatação de que os paradigmas positivista e estruturalista são apenas os critérios de legitimação do conhecimento ocidental e eurocentrista e excluem de forma sistemática a diversidade local (Tabela1). O paradigma positivista ortodoxo, por exemplo, só considera fatos geográficos reconhecidos, os espaços com uma configuração geométrica quadricular que incluam a superfície, polígonos regulares, linhas retas e pontos. À realidade não padronizada pela economia ocidental e todo o comportamento e interpretação não ocidental, não tem sido dado o devido valor geográfico. A inclusão dentro do corpo de conceitos geográficos ainda necessita de certa conformação com um padrão pré-estabelecido sempre simplificado, enquadrável em modelo pré-concebido. Em Moçambique, a interpretação reducionista bastante esquemática sobre uma realidade exótica, cheia de atributos negativos, foi idealizada durante o período colonial e perdura até hoje nos manuais de Geografia e nos Programas Escolares. Essa concepção foi bastante difundida após a segunda guerra mundial, com a ideia de que ao caracterizar o espaço geografico interfere um desejo inculcado de reproduzir uma paisagem convencional a partir do ponto de vista ocidental. Por isso, actualmente notamos com frequência que no ensino da geografia e na tentativa de produzir monografias predominam afirmações recriminadoras e não inclusivas do espaço, quando este não tiver sido transformado pela lógica ocidental de mercado.

Por essa razão em Moçambique os conceitos de desenvolvimento, ou mesmo de pobreza produzem 
sempre conflitos de interpretação sobre o que se considera que seja evidência para o espaço geográfico. $\mathrm{O}$ paradigma da diversidade pretende, através deste diagnóstico, promover um tipo alternativo de interrogações sem apriorismos. Considera que a concepção do desenvolvimento e de risco não podem ser universais e não problemáticos.

O paradigma da diversidade e da inclusão tem o seu suporte nas diferentes correntes da Geografia surgidas na segunda metade do século XX, principalmente na Geografia Crítica, cujo representante na expressão portuguesa é o geógrafo Milton Santos, na geografia Humanista e Cultural, incluindo a corrente fenomenológica que se baseia no pensamento do filósofo Maurice Ponty. Estas contribuições defendem a causação mútua do sujeito e do objeto numa interatividade dinâmica (Rodriguez, Silva e Cavalcanti, 2007). Esta dinamicidade interartiva espácio-temporal resulta em diferentes paisagens, reconfigurações regionais em diferentes escalas (incluindo as chamadas microterritorialidades), algumas das quais ausentes mas transportadas pelo sujeito e recriadas nos espacos de convivência, os lugares(Fortuna, 2012). (Tabela 1)

Tabela 1.Comparação entre o paradigma positivista e estruturalista o paradigma da diversidade e inclusão

\begin{tabular}{|c|c|}
\hline $\begin{array}{l}\text { Paradigma positivista-estruturalista } \\
\text { Suporte do neoliberalismo e da globalização }\end{array}$ & $\begin{array}{l}\text { Paradigma da diversidade e complexidade } \\
\text { Suporte do desenvolvimento Sustentável }\end{array}$ \\
\hline Causa-efeito & $\begin{array}{l}\text { Interação e complementaridade, causação mútua das } \\
\text { variáveis. }\end{array}$ \\
\hline Linearidade & $\begin{array}{l}\text { Complexidade, multiplicidade de causas que } \\
\text { necessitam da inclusão }\end{array}$ \\
\hline Diferenciação & $\begin{array}{l}\text { Diversificação, os elementos são também } \\
\text { heterogéneos. }\end{array}$ \\
\hline Crescimento & Sustentabilidade \\
\hline $\begin{array}{l}\text { Homogeneidade dos elementos constituintes do meio } \\
\text { geográfico }\end{array}$ & $\begin{array}{l}\text { Diversidade, propriedades do todo nas partes e das } \\
\text { partes no todo, polimorfismo }\end{array}$ \\
\hline Lei objectiva estruturante da realidade & $\begin{array}{l}\text { Existência de regularidades Representações e } \\
\text { perceções }\end{array}$ \\
\hline Existência do Físico, Não humano & $\begin{array}{l}\text { Ecológico, interactivo, determinação mútua da natureza } \\
\text { e do homem }\end{array}$ \\
\hline Previsibilidade a partir de modelos & Imprevisibilidade, caos, diversidade \\
\hline Estruturas Sociais & $\begin{array}{l}\text { Identidades culturais sociais e territoriais: } \\
\text { Sociodiversidade }\end{array}$ \\
\hline Reducionismo, modelos matemáticos rígidos & $\begin{array}{l}\text { Holismo: análise complexa da diversidade na } \\
\text { compreensão da totalidade }\end{array}$ \\
\hline Determinação de Uniformidade & Inclusão de singularidade nuances \\
\hline
\end{tabular}

Fonte: (ex. Leff, 2004; Rodriguez et all. 2007) 


\section{A SEMELHANÇA ESTRUTURAL DO CONTEÚDO DA DIVERSIDADE GEOGRÁFICA}

\section{GEODIVERSIDADE}

O conceito geodiversidade foi utilizado pela primeira vez em 1993, na Conferencia sobre Conservação Geológica Paisagística em Malverm, no Reino Unido (Brilha, 2005). O primeiro livro sobre geodiversidade foi escrito em 2004 pelo Departamento de Geografia da Universidade de Londres (Brilha,2005). Compreende este conceito a variedade de ambientes geológicos, fenômenos e processos ativos geradores de paisagens, rochas, minerais, solos e outros depósitos superficiais que constituem a base da vida na Terra. A geodiversidade compreende todos os aspectos abióticos estudados tradicionalmente pela geografia física geral (Brilha,2005).

Ao contrário do termo biodiversidade, termo análogo relativo a variabilidade nos seres vivos, o termo geodiversidade não é de uso tão alargado mesmo entre os geólogos. O carácter aparentemente inerte da diversidade geológica pode ser a maior causa do pouco uso deste conceito. Um dos exemplos que se pode tomar é a fraca aplicabilidade do conceito no meio aquático e oceânico. (Brilla, 2005).

Contudo o conceito geodiversidade possui semelhança estrutural com outros conceitos baseados no paradigma da diversidade, como é o caso do de Biodiversidade e de Sociodiversidade, por constituir o fundamento de toda a diversidade geográfica da superfície terrestre, ao exprimir o processo e o resultado da longa história da evolução da terra através de ciclos geológicos e biogeoquímicos que garantem a vida na terra. As rochas e os minerais extraídos pelo homem e postos em circulação são a causa da degradação ambiental por interferirem com os ciclos biológicos normais em elevadas concentrações, ultrapassando a concentração limite admissível nas águas, no solo, na atmosfera e no organismo dos seres vivos e dos seres humanos (Tabela 2).

\section{BIODIVERSIDADE}

O conceito biodiversidade integra toda a variabilidade entre os organismos vivos, incluindo genes, espécies, população e ecossistemas. A diversidade de espécies refere-se à variedade existente dentro de uma região, partilhando a mesma estrutura genética e reproduzindo-se entre si (Ferrão, 2010).

Um grupo de indivíduos da mesma espécie forma uma população, mas os indivíduos de uma população não são idênticos por possuirem uma herança genética própria. Uma mesma espécie possui populações diferentes devido à variabilidade genética dentro duma população (Ferrão, 2010). Esta variabilidade é importante na produção de alimentos e na medicina, na medida em que $90 \%$ das necessidades de alimentação são garantidas por 20 espécies de plantas e suas variedades. As variedades e raças são importantes do ponto de vista da sociodiversidade, na medida em que resultam da seleção artificial e contribuem para a identidade das comunidades e povos, permitindo a complementaridade e a troca de produtos para a dieta alimentar (Ferrão, 2010).

\section{SOCIODIVERSIDADE}

A sociodiversidade é um conceito largamente utilizado no Brasil e é aplicável para os povos indígenas mas que, por analogia com a geodiversidade e a biodiversidade, possui um poder explicativo aliciante no que 
toca à diversidade da cultura material, de produção de estilos de vida, de padrões de organização social e de espaço. A organização dos estilos de vida produz comportamentos territoriais. Nesse processo uns estilos de vida tentam se impor sobre os outros, originando consciente ou inconscientemente a diminuição das manifestações de alguns estilos de vida e a aumento de outros, o que produz cada vez mais a uniformização(Melo,2002). A educação formal, quando não reconhece estas diferenças, é um dos agentes principais da erosão cultural. O paradigma da diversidade e da inclusão pode beneficiar do erro desta corrente e sua caracterização é feita na tabela 2 .

Tabela 2 Os Meta-conceitos Geodiversidade, Biodiversidade e Sociodiversidade, sua analogia e semelhança estrutural.

\begin{tabular}{|c|c|c|c|}
\hline Tipo & Geodiversidade: & Biodiversidade & Sociodiversidade \\
\hline Características & $\begin{array}{l}\text { Minerais rochas, formas } \\
\text { de relevo, águas, meio } \\
\text { abiótico junto à superfície } \\
\text { terrestre que inclui micro- } \\
\text { clima }\end{array}$ & $\begin{array}{l}\text { Genes espécies, } \\
\text { populações, ecossistemas }\end{array}$ & $\begin{array}{l}\text { Grupo de pessoas, comunidades, } \\
\text { camadas sociais, nações, raças, } \\
\text { religiões, organizações sociais, } \\
\text { instituições, patrimônio histórico- } \\
\text { cultural }\end{array}$ \\
\hline Ameaças & $\begin{array}{l}\text { Ameaçada pela erosão } \\
\text { acelerada e pela } \\
\text { terraplanagem } \\
\text { conducentes à } \\
\text { uniformização ao nível } \\
\text { local }\end{array}$ & $\begin{array}{l}\text { Ameaçada pela erosão da } \\
\text { biodiversidade, extinção } \\
\text { das espécies e pela } \\
\text { urbanização conducentes à } \\
\text { uniformização ao nível } \\
\text { local }\end{array}$ & $\begin{array}{l}\text { Ameaçada pela erosão cultural } \\
\text { provocada pela globalização }\end{array}$ \\
\hline Impactos & $\begin{array}{l}\text { Impactos da destruição da } \\
\text { geodiversidade: } \\
\text { Assoreamento dos rios e } \\
\text { lagos, diminuição da } \\
\text { biodiversidade, perda da } \\
\text { memória da história global } \\
\text { e local }\end{array}$ & $\begin{array}{l}\text { Impactos da perda da } \\
\text { biodiversidade: } \\
\text { Perda da informação } \\
\text { genética para cruzamento } \\
\text { de plantas, produção de } \\
\text { alimentos e medicamentos, } \\
\text { biotecnologias }\end{array}$ & $\begin{array}{l}\text { Impacto da perda da } \\
\text { sociodiversidade: perda de } \\
\text { conhecimento sobre a natureza e } \\
\text { sociedade, perda de valores éticos e } \\
\text { visões do mundo }\end{array}$ \\
\hline $\begin{array}{l}\text { Formas de } \\
\text { valorização }\end{array}$ & $\begin{array}{l}\text { Pode ser preservado em } \\
\text { forma de património } \\
\text { geológico ou geossítio } \\
\text { Exemplo: Grutas de } \\
\text { Khundue }\end{array}$ & $\begin{array}{l}\text { Pode ser preservada em } \\
\text { parques nacionais e } \\
\text { reservas } \\
\text { Exemplo: Parque Nacional } \\
\text { da Gorongosa }\end{array}$ & $\begin{array}{l}\text { Pode ser preservada em aldeias } \\
\text { culturais, museus e lugares } \\
\text { patrimônio da humanidade como a } \\
\text { Ilha de Moçambique, Dança Nhau, } \\
\text { Musica Timbila }\end{array}$ \\
\hline
\end{tabular}

Fonte: (ex. Ferrão, 2005; Brilha 2010). 


\section{A INTERAÇÃO DAS DIVERSIDADES:}

De acordo com Guillermo Grisales do Grupo de Estudos Estratégicos Amazônicos, por exemplo, tanto a Declaração Universal Sobre Diversidade Cultural, como a Convenção Internacional Sobre a Proteção e Promoção da Diversidade das Expressões Culturais reconhecem que a diversidade cultural (sociodiversidade) é um patrimônio comum da Humanidade, tão necessária para o gênero humano quanto a biodiversidade. Sabe-se também que ao nível dos ecossistemas, a biodiversidade resulta da interação dos seres vivos com o seu meio abiótico, meio esse que produz a biodiversidade e a geodiversidade. Isto demonstra como os fatores abióticos determinam a biodiversidade e como esta influi naqueles, demonstrando igualmente a necessidade de se adoptar o paradigma da diversidade e da inclusão.

Em Moçambique a falta de um paradigma de diversidade faz-se sentir nos megaprojectos, onde a perseguição de um grande objetivo económico reduz as componentes do contexto onde o projeto ocorre a simples palco. Os grupos humanos transformam-se em simples comunidades para as quais se pode aplicar uma mesma fórmula resolvente, pese os estudos de impacto ambiental se esforçarem em reconhecer a sociodiversidade ao investigar, por exemplo, aspectos como a etnobotânica e a etnozoologia. Eis a razão de a realidade complexa local ser considerada uma situação de referência.

Em estudos realizados no Parque da Gorongosa e do Limpopo ficou patente que o que chamamos de comunidades possui uma composição heterogênea quanto ao acesso à diversidade de recursos, incluindo a localização em relação as formas de relevo local, a vulnerabilidade aos eventos naturais extremos e ao acesso às fontes de subsistência. Eis a razão por que fomos tentados a considerar que o conflito homem-animal constitui um conflito entre homens no que diz respeito à diversidade de seus posicionamentos quanto à capacidade de tirar vantagens a partir da conservação e interpretação da natureza biodiversa que se pretende proteger. Ocorre um conflito de prioridades que não sendo tomado em consideração pode prejudicar a convivência entre as comunidades caracterizadas pela diversidade social juntamente com os interesses ecológicos e económicos dos operadores e dos turistas. O simples facto de a permanência, quer dos operadores quer dos turistas, ser temporária leva a uma interrogação sobre uma possível igualdade de circunstância com as comunidades quanto á influência dos animais nas suas vidas.

A não consideração da diversidade numa sociedade democrática de livre expressão conduz sempre a confrontos e emergência de novas identidades coletivas, como as ONGs que ao nível internacional servem de representantes dos interesses locais.

\section{MOÇAMBIQUE GEODIVERSO}

A diversidade é uma das características mais notórias da Geografia de Moçambique. O país é essencialmente diverso no substrato geológico, nas formas de relevo, na densidade e diversidade do regime de águas superficiais e subterrâneas, incluindo a variabilidade climática e da linha da costa. A diversidade da flora e da fauna reflete a diversidade dos ambientes abióticos dentro da geodiversidade. A diversidade de Moçambique manifesta-se também do ponto de vista étnico e cultural sendo, em certa medida, resultante da miscigenação dos nativos com gentes de muitas partes do mundo ao longo da história, incluindo a ocupação colonial. A abertura aos investimentos externos e a imigração interna legal e ilegal resulta num aumento cada vez maior da 
diversidade étnica, racial, linguística e cultural.

Diante desta realidade, o paradigma da diversidade e o seu poder explicativo aliciante ganha maior espaço na apreciação da realidade moçambicana, operacionalizando-se pelo emprego dos conceitos geodiversidade, biodiversidade e sociodiversidade que possuem o potencial de, ao mesmo tempo em que exprimem o engajamento político-social da geografia, sugerir também ferramentas de análise para uma intervenção engajada que pode promover uma maior atenção nos aspectos naturais e humanos a escala local e, ao mesmo tempo, negociar a sua inclusão nos processos de ensino e na pesquisa.

Um outro propósito desta reflexão consiste em sugerir que se revitalize a Geografia em Moçambique de modo a que se torne mais interativa, mais interrogadora da realidade que estuda, permitindo revelar as suas diferentes facetas de modo a extrair-se um leque cada vez maior de oportunidades para a satisfação das necessidades materiais e espirituais das pessoas.

A globalização tecnológica, ao mesmo tempo que produz a hegemonia do capital e a erosão cultural, traz também ferramentas que funcionam ao contrário, que facilitam o estudo pormenorizado da diversidade geológica, biológica e social devido ao recurso ao GIS para o mapeamento dos particularismos locais(Melo, 2002). O uso do GPS por exemplo é bastante divulgado no levantamento de objetos localizados. As imagens de satélite permitem acompanhar as particularidades das dinâmicas locais, as reações diferencias dos espaços, os fenómenos extremos causadas pela geodiversidade, os diferentes usos da biodiversidade e a influência da sociodiversidade (Tabelas 3 e 4).

A agricultura, o seu estudo e ensino, ainda revela elevados 50 graus de reducionismo e exclusão como atesta a caixa 1. O interesse suscitado pelo debate à volta dos recursos minerais descobertos, com o poder de produzir espaços globalizados e criar configurações espaciais modernas, contribui ainda para execução de espaços aparentemente pouco expressivos, mas que alberguem a maioria da população moçambicana (Lopes, 2013).

\section{O PARADIGMA DA DIVERSIDADE NA PESQUISA E NO ENSINO}

A diversidade difere muito da complexidade. A complexidade é uma propriedade inerente aos objetos enquanto a diversidade enfatiza a diferença entre objetos individualizáveis, podendo ser regiões, comunidades ou indivíduos. O paradigma da diversidade visa enfatizar a variabilidade quase ilimitada de possibilidades dos resultados das interações dos homens entre si e com o meio, incluindo as do meio para com o meio (Wamsley, 2012). Os aspectos a considerar na interação de entidades em escalas diferentes dependem das perguntas que os investigadores colocam. Quanto maior for o interesse da consideração desta diversidade maior será a probabilidade de encontrar respostas mais adequadas para a solução dos problemas (Wamsley, 2012).

Por causa da diversidade nas motivações das ações humanas e das formas como as praticam, os efeitos serão diferentes e irão produzir também impactos que, se forem materiais, modificarão a paisagem, produzindo regiões e lugares. Chama-se a atenção de que é importante para perspectivar o futuro saber como é que as pessoas chegaram aos resultados a que chegaram, para avaliar a sua sustentabilidade e não apenas o resultado em si ou a aparência que as coisas têm. Assim, paisagens com aparecias semelhantes podem ter destinos distintos. 


\section{A EXCLUSÃO DO TEMA SOBRE A AGRICULTURA DE MOÇAMBIQUE NOS MANUAIS DE ENSINO}

No nosso país a agricultura tradicional tem sido tratada de forma reducionista e esquemática, o que esconde a diversidade de situações influenciadas pela geodiversidade, biodiversidade e sociodiversidade. $\mathrm{O}$ papel dos manuais de Geografia para além da caracterização dos traços gerais deveria incluir alguma caracterização da dinâmica da agricultura, sua ligação, por exemplo, com o povoamento e as vias de comunicação, entre outros fatores.

A vida rural, por exemplo, envolve a caça e a coleta de vários produtos. Nos manuais de Geografia escolar, esta atividade de coleta, quer dos produtos florestais quer dos frutos do mar, é praticamente ausente, apesar de servir de fonte de rendimento e de sustento a centenas de milhões de pessoas. Seria importante, por exemplo, indicar a atividade extrativa dos recursos florestais e minerais como fonte de materiais de construção ligadas ao povoamento e a outros hábitos culturais.

Os exemplos da simplificação podem ser apresentados nos seguintes trechos dos livros de Geografia em uso em Moçambique:

\section{CAIXA 1}

Livro A:

Tema:Características da agricultura de subsistência:

Em Moçambique, a agricultura e caracterizada por....

Utilização de métodos rudimentares de trabalho, sistema promíscuo de culturas, e praticada usando a enxada e ou a charrua.

Livro B

Tema: Características da agricultura de subsistência e de plantação

De Subsistência;

Técnicas de cultivo rudimentares, transmitidas de geração em geração

Produtividade agrícola baixa, considerando que para se produzir uma pequena produção emprega-se uma grande quantidade de mão-de-obra

Rendimento agrícola baixo às técnicas rudimentares usadas.

Destino da produção, maioritariamente, para autoconsumo, isto é, tendo como finalidade principal alimentar o agricultor e sua família.

Estas características de subsistência vêm desde o tempo colonial e são apresentadas de forma pejorativa, sem nenhuma tentativa de descrever a forma concreta de sua manifestação em território Moçambicano. Neste aspecto sente-se a falta de interação entre a investigação agronômica e o ensino. A extensão agrícola e a atividade investigativa têm logrado modificar a produtividade das culturas como, por exemplo, a introdução de novas variedades de mandioca, batata-doce etc., mesmo na agricultura familiar tradicional.

Um dos aspectos importantes a considerar na agricultura é a especialização, em algumas regiões do país, que não envolve a consorciação de culturas mesmo quando a agricultura é de subsistência. Estas caracterizações também ignoram o crescente envolvimento dos camponeses na comercialização das culturas, 
como é o caso do milho, do feijão e das hortícolas. Ao longo das vias de comunicação é bem visível uma monocultura destinada ao comércio que envolve a presença de povoados informais de comercialização de produtos. É ainda notória a venda de excedentes. A crescente monetarização da economia e a presença cada vez mais visível de produtos industriais aumentou a necessidade de produção para o mercado (Uaene, 2012).

O Ministério da Agricultura, por exemplo, tem um programa de comercialização agrícola que acompanha os mercados e preços dos produtos agrícolas. Estas considerações são de extrema importância na consideração da agricultura em Moçambique (Uaene, 2012).

A ligação estreita agricultura-povoamento-vias de acesso-comercialização tem suas raízes no tempo colonial, e sua não consideração durante o período da socialização do campo, das aldeias comunais e machambas estatais conduziu, de acordo com alguns analistas, à dissolução da economia rural.

Quando se aborda a economia rural deve-se incluir as manifestações da vida econômica e social influenciadas profundamente pela cultura numa abordagem dinâmica e inclusiva. No Sul de Moçambique, por exemplo, onde incidiram os estudos dos impactos desta dissolução inclui-se a influência estruturante do trabalho migratório para a África do Sul (Ombe, 2006). Esta análise também inclui a interação entre as atividades do sector familiar e o trabalho assalariado nas cidades e nas plantações (Ombe, 2006). Aqui há que realçar o caráter interativo e não aditivo das diferentes atividades ocorrendo em diferentes contextos geográficos, reforçando a ideia do caráter geodiverso das economias rurais descritas de forma simplista na caixa 1 (Ellis e Aliison, 2004). A educação geográfica em Moçambique herdou da concepção errónea que se construiu durante varias décadas que identificou os camponeses como empresários falidos. Nos alvores das independências africanas o debate sobre o futuro da agricultura tradicional centrava-se em torno de duas tendências: uma, capitalista, que considerava que a pequena propriedade camponesa tendia a desaparecer dando lugar a grande empresa agrária capitalista e outra dos países de orientação socialista, em que a pequena propriedade camponesa daria lugar a empresa estatal ou cooperativa. Passados 50 anos das independências africanas a agricultura tradicional continua a ocupar a maioria esmagadora da população rural, estendendo-se muitas vezes para espaços livres urbanos.

Estudos recentes chamam a atenção de que os chamados camponeses não são necessariamente agricultores falidos no sentido de empresários mal sucedidos. Eles são simplesmente habitantes das regiões rurais que possuem a agricultura como ocupação disponível e que, historicamente, mantem-se por não ter havido processos de industrialização que a intensificassem e movesse esta massa para os sectores secundário (indústria) e terciário (serviços) da economia. Sendo assim a Geografia, para além de estudar a agricultura, deveria caracterizar o padrão da vida urbana sob pena de não retratar a forma de estar em Moçambique ao caracterizar a maioria dos moçambicanos com variações regionais que carecem de estudo e reflexão sobre suas origens e potencial de mudança.

Um dos grandes danos à apreciação da diversidade ocorre devido à tendência constante para a desterritorialização e reterritorialização em Moçambique (Haesbaert, 2010). Estes dois processos indissociáveis ocorrem tanto nos espaços urbanas quanto nos rurais, com a constante expansão das cidades que convertem territórios e lugares rurais, com as suas dinâmicas peculiares, em áreas residenciais com novos moradores incluindo novos estilos de vida. A palavra reassentar significa assentar de novo, ou seja, desterritorializar ou mover e reterritorializar ou assentar em novos territórios (Haesbaert, 2010). Este processo também ligado a emergência de grandes projetos mineiro-energéticos (Megaprojectos) possui um grande potencial para a transformação da paisagem (Lopes, 2013). 
Os megaprojectos mineiro-energéticos trazem, por exemplo, um padrão de distribuição espacial das atividades económicas reticulares e nodais próprias dos países industrializados, atravessando espaços rurais e semi-urbanizados dominados pela agricultura tradicional e pelo extrativismo dos recursos da geodiversidade e da biodiversidade

O poder que tem os meios de comunicação no que diz respeito à moda e ao consumo virtual distrai-nos da apreensão do mundo real. A facilidade de nos comunicarmos via skype distrai-nos da necessidade de construir estradas e pontes e de interessar as jovens gerações em investir na pesquisa sobre temas mais relevantes. Um exemplo concreto é o paradoxo de mulheres comprando mobília na china e chineses retirando-nos madeira, enquanto as nossas escolas estão sem carteiras, o que banaliza o nosso ensino.

A facilidade com que a madeira sai de Moçambique em contentores contrasta com as dificuldades de encontrar transporte de casa para o trabalho. Quando, em Maputo, tentou-se introduzir um barco para o transporte urbano, este não teve clientes por falta do poder de compra. A geografia da inclusão chama atenção para a consideração da maneira específica como as leis operam que é muitas vezes ao contrário em Moçambique. Por exemplo o trem, considerado meio mais acessível é preterido para se ir de "vans" porque a quantidade de produtos e pessoas transportadas não compensa o uso do comboio, constituindo isso um retrocesso. O paradigma da diversidade chama a atenção para três tipos de questões: quem, como e porquê. Por exemplo, porquê é que são evitadas as infraestruturas formais dos centros das vilas para os agentes do comercio informal e formal se concentrarem em barracas na periferia dos povoados (Ombe, 2006).

\section{O PARADIGMA DA DIVERSIDADE E O CURRÍCULO LOCAL}

O ensino necessita de uma geografia mais inclusiva e que explore o princípio da variação da escala de forma crítica e criativa, de modo a eleger evidências de diferentes níveis de organização e complexidade e a se preocupar com as nuances e não apenas com as regularidades.

De acordo com a UNESCO, o saber local que se manifesta na interpretação dos fenômenos e nas práticas do agir cotidiano constitui um repositório de diversidade e um recurso chave para se entender a realidade mais próxima do aluno, como, por exemplo, o lugar, que pode utiliza-lo no seu próprio interesse e no da comunidade (UNESCO, 2005). Este saber, no contexto da aprendizagem, permite aos alunos deduzir do seu próprio meio os conceitos científicos, estabelecendo relações entre os conhecimentos endógeno e universal do currículo nacional.

O uso da língua local na educação é um fator não apenas de equilíbrio no desenvolvimento cognitivo das crianças mas também de reconhecimento e validação das ligações entre as matérias estudadas na escola e fatos tirados diretamente do quotidiano e da comunidade(UNESCO, 2005).

É necessário realçar que endógeno não significa estático. Significa sim um conhecimento produzido em estreita ligação com fatores do contexto local que servem de crivo para sua validação e sobrevivência ao longo da história.

Como resposta ao problema do reducionismo e de exclusão na caracterização da agricultura tradicional e da vida rural em geral, sugere-se uma análise crítica das tabelas 3 e 4 que comparam estes tipos de agricultura. 
Tabela 3: Comparação entre as características das agriculturas moderna e tradicional praticada em Moçambique com variações regionais, tomando em consideração o paradigma da diversidade.

\begin{tabular}{|c|c|c|c|}
\hline $\begin{array}{l}\text { Parâmetro ou } \\
\text { característica da } \\
\text { agricultura }\end{array}$ & $\begin{array}{l}\text { Agricultura } \\
\text { moderna }\end{array}$ & $\begin{array}{l}\text { Prática tradicional na Africa } \\
\text { Austral }\end{array}$ & Comentários \\
\hline $\begin{array}{l}\text { Preparação do } \\
\text { terreno ou cultivo }\end{array}$ & $\begin{array}{l}\text { Num período fixo, } \\
\text { usando tratores e } \\
\text { grades, nivelando o } \\
\text { terreno }\end{array}$ & $\begin{array}{l}\text { Uso da enxada e tração } \\
\text { animal, varias vezes ao ano, } \\
\text { sempre que for necessário. O } \\
\text { terreno mantém } \\
\text { microtopografias }\end{array}$ & $\begin{array}{l}\text { O terreno pode ter por exemplo } \\
\text { termiteiras e árvores }\end{array}$ \\
\hline Sementeira & $\begin{array}{l}\text { Em meses } \\
\text { recomendados pelos } \\
\text { agrónomos e uma } \\
\text { quantidade fixa de } \\
\text { sementes por hectare }\end{array}$ & $\begin{array}{l}\text { Sempre que for necessário } \\
\text { devido à variabilidade da } \\
\text { precipitação }\end{array}$ & $\begin{array}{l}\text { Ao longo do ciclo do crescimento de } \\
\text { plantas podem ocorrer secas de curta } \\
\text { duração exigindo repetição das } \\
\text { sementeiras }\end{array}$ \\
\hline $\begin{array}{l}\text { Variedade de } \\
\text { sementes }\end{array}$ & $\begin{array}{l}\text { Uma ou duas } \\
\text { variedades } \\
\text { recomendadas, } \\
\text { geralmente fixas }\end{array}$ & $\begin{array}{l}\text { Variedades locais resistentes a } \\
\text { seca }\end{array}$ & $\begin{array}{l}\text { Devido a razões de várias ordens } \\
\text { como conflitos e desastres naturais, } \\
\text { muitas variedades locais foram } \\
\text { substituídas por sementes melhoradas } \\
\text { as vezes pouco adaptadas às } \\
\text { condições locais }\end{array}$ \\
\hline $\begin{array}{l}\text { Gestão da } \\
\text { fertilidade }\end{array}$ & $\begin{array}{l}\text { Um tipo e quantidade } \\
\text { fixa de fertilizantes } \\
\text { cientificamente } \\
\text { calculada }\end{array}$ & $\begin{array}{l}\text { Aplicações pontuais de } \\
\text { fertilizantes, uso da fertilidade } \\
\text { natural, as vezes usando } \\
\text { excrementos do gado para } \\
\text { hortícolas }\end{array}$ & $\begin{array}{l}\text { Enquanto a localização do esforço } \\
\text { agrícola da agricultura moderna é } \\
\text { intensiva e fixa, na agricultura } \\
\text { tradicional é extensiva e móvel. } \\
\text { Vários campos são cultivados com } \\
\text { plantas de diferentes idades. }\end{array}$ \\
\hline Monda $^{2}$ & $\begin{array}{l}2 \text { mondas por } \\
\text { campanha }\end{array}$ & $\begin{array}{l}\text { As mondas dependem do } \\
\text { comportamento da } \\
\text { precipitação e das diferentes } \\
\text { sementeiras nas diferentes } \\
\text { machambas }^{3}\end{array}$ & $\begin{array}{l}\text { Diferentemente da agricultura } \\
\text { moderna a tradicional recorre a } \\
\text { improvisações e é oportunista }\end{array}$ \\
\hline Controlo de pragas & $\begin{array}{l}\text { Uso intensivo de } \\
\text { inseticidas }\end{array}$ & $\begin{array}{l}\text { Não uso de inseticidas ou sua } \\
\text { aplicação pontual em caso de } \\
\text { necessidades }\end{array}$ & $\begin{array}{l}\text { Os inseticidas são de origem } \\
\text { biológica, explicando os recursos } \\
\text { locais }\end{array}$ \\
\hline Compasso agrícola & $\begin{array}{l}\text { Uma distância } \\
\text { recomendada } \\
\text { dependendo da }\end{array}$ & $\begin{array}{l}\text { Consorciação de culturas, } \\
\text { havendo em cada machamba } \\
\text { distâncias diferentes }\end{array}$ & $\begin{array}{l}\text { A mistura premeditada de culturas na } \\
\text { agricultura tradicional evita a perda } \\
\text { total da sementeira por causa da }\end{array}$ \\
\hline
\end{tabular}




\begin{tabular}{|c|c|c|c|}
\hline & $\begin{array}{l}\text { quantidade de } \\
\text { sementes por hectare. } \\
\text { Pratica-se a } \\
\text { monocultura }\end{array}$ & $\begin{array}{l}\text { dependendo das culturas e da } \\
\text { fertilidade dos solos }\end{array}$ & $\begin{array}{l}\text { variabilidade da precipitação, permite } \\
\text { ainda a exploração das diferentes } \\
\text { profundidades do solo }\end{array}$ \\
\hline $\begin{array}{l}\text { Rotação das } \\
\text { culturas }\end{array}$ & $\begin{array}{l}\text { Recomendada } \\
\text { cientificamente; Por } \\
\text { exemplo, milho- } \\
\text { sorgo-leguminosas }\end{array}$ & $\begin{array}{l}\text { Na maioria dos casos não há } \\
\text { rotação. Para a recuperação da } \\
\text { fertilidade pratica-se o pousio } \\
\text { de } 1 \text { a } 10 \text { anos }\end{array}$ & $\begin{array}{l}\text { Nas regiões de fraca densidade } \\
\text { populacional pratica-se a agricultura } \\
\text { itinerante de queimada, cultura e } \\
\text { abandono prolongado }\end{array}$ \\
\hline Agroflorestamento & $\begin{array}{l}\text { Não existe. Todas as } \\
\text { árvores são cortadas }\end{array}$ & $\begin{array}{l}\text { As árvores, principalmente de } \\
\text { fruta, são deixadas nos } \\
\text { campos }\end{array}$ & $\begin{array}{l}\text { Na agricultura tradicional as árvores } \\
\text { nos campos são infraestruturas para } \\
\text { descanso, processamento de } \\
\text { produtos, proteção do sol durante a } \\
\text { caminhada. São também marcos para } \\
\text { delimitar propriedades. }\end{array}$ \\
\hline $\begin{array}{l}\text { Gestão da } \\
\text { humidade do solo }\end{array}$ & $\begin{array}{l}\text { Cultivo profundo, } \\
\text { presença de sulcos }\end{array}$ & $\begin{array}{l}\text { Cultura em camalhões e } \\
\text { variedade de técnicas de } \\
\text { acordo com as necessidades }\end{array}$ & $\begin{array}{l}\text { A gestão da humidade envolve } \\
\text { também o cultivo de diferentes } \\
\text { plantas com diferentes exigências de } \\
\text { humidade }\end{array}$ \\
\hline $\begin{array}{l}\text { Conservação do } \\
\text { solo }\end{array}$ & $\begin{array}{l}\text { Cultivo em curvas de } \\
\text { nível, alas florestais } \\
\text { de eucaliptos e } \\
\text { pinheiros nos limites } \\
\text { das propriedades }\end{array}$ & $\begin{array}{l}\text { Agroflorestamento onde as } \\
\text { arvores protegem o solo da } \\
\text { erosão hídrica e eólica. Em } \\
\text { algumas regiões há projetos } \\
\text { que aconselham o cultivo sem } \\
\text { revolver a terra. A enxada não } \\
\text { abre sulcos como as charruas e } \\
\text { discos dos tratores } \\
\text { minimizando a erosão }\end{array}$ & $\begin{array}{l}\text { Pode incluir a não retirada dos caules } \\
\text { depois da colheita. Nas margens dos } \\
\text { rios podem ser preferidas plantas } \\
\text { rastejantes como a abobora a batata- } \\
\text { doce e o tomateiro tradicional. }\end{array}$ \\
\hline
\end{tabular}


Tabela 4: comparação entre a criação de gado moderna e as formas tradicionais que evidenciam a diversidade.

\begin{tabular}{|c|c|c|c|}
\hline $\begin{array}{l}\text { Actividade } \\
\text { Pecuária }\end{array}$ & $\begin{array}{l}\text { Versão } \\
\text { convencional }\end{array}$ & Formas tradicionais & Comentários \\
\hline Objectivos & Produção da carne & $\begin{array}{l}\text { Usos múltiplos, cerimoniais } \\
\text { tradicionais, mitigações de } \\
\text { riscos de seca e tração animal. }\end{array}$ & $\begin{array}{l}\text { Gado como forma de mitigação de } \\
\text { riscos naturais e sociais, símbolo de } \\
\text { prestígio e perseverança, usado para } \\
\text { processos de socialização, escola da } \\
\text { vida e para vida. }\end{array}$ \\
\hline $\begin{array}{l}\text { Capacidade } \\
\text { recomendada de } \\
\text { pastagem }\end{array}$ & 10ha por cabeça & $\begin{array}{l}\text { Não existe uma área fixa de } \\
\text { pastagem por cabeça, } \\
\text { recorrendo-se a mobilidade } \\
\text { para minimizar as secas e as } \\
\text { cheias }\end{array}$ & $\begin{array}{l}\text { A criação de gado não é apenas para } \\
\text { carne a as pastagens não tem como } \\
\text { objectivo apenas a engorda. }\end{array}$ \\
\hline $\begin{array}{l}\text { Gestão da } \\
\text { pastagem }\end{array}$ & Rotação & $\begin{array}{l}\text { Mobilidade, uso de diferentes } \\
\text { zonas ecológicas recorrendo a } \\
\text { redes sociais. }\end{array}$ & $\begin{array}{l}\text { O contato com as realidades sócio- } \\
\text { espaciais deferentes tornam o } \\
\text { processo da criação de gado social e } \\
\text { cultural e não meramente negócio. É } \\
\text { uma das manifestações da } \\
\text { sociodiversidade, explorando a } \\
\text { geodiversidade e a biodiversidade ao } \\
\text { longo das paisagens }\end{array}$ \\
\hline Gestão de rações & $\begin{array}{l}\text { Recorrendo a } \\
\text { rações industriais }\end{array}$ & $\begin{array}{l}\text { Não uso de rações, mas uso } \\
\text { de restolho após a colheita, } \\
\text { utilização de folhas de } \\
\text { arvores e arbustos como pasto } \\
\text { em tempos de crise }\end{array}$ & $\begin{array}{l}\text { É importante a complementaridade } \\
\text { entre a agricultura e a pecuária. } \\
\text { Algumas terras em pousio são } \\
\text { usadas para apascentar o gado } \\
\text { alimentando-se de caules e folhas } \\
\text { secas do milho, por exemplo. }\end{array}$ \\
\hline $\begin{array}{l}\text { Reação durante } \\
\text { secas }\end{array}$ & Abates & $\begin{array}{l}\text { Mobilidade, migração do } \\
\text { gado para regiões mais } \\
\text { húmidas, recorrendo a } \\
\text { familiares e amigos }\end{array}$ & $\begin{array}{l}\text { A mobilidade espacial como } \\
\text { resposta a contingências exige a } \\
\text { cultura de solidariedade e uso das } \\
\text { complementaridades dos espaços } \\
\text { causados por exemplo, pela } \\
\text { geodiversidade. }\end{array}$ \\
\hline $\begin{array}{l}\text { Controle de } \\
\text { doenças }\end{array}$ & $\begin{array}{l}\text { Controle de } \\
\text { movimento, banhos } \\
\text { caraticidas } \\
\text { antibiótico }\end{array}$ & $\begin{array}{l}\text { Uso de ervas tradicionais, uso } \\
\text { de tanques caraticidas } \\
\text { públicas e pulverizadores } \\
\text { caseiros }\end{array}$ & $\begin{array}{l}\text { Recurso a conhecimentos locais } \\
\text { aproveitando a biodiversidade }\end{array}$ \\
\hline Animais de & Pouco praticadas & Criação de cabritos, coelhos, & Animais de pequeno porte são um \\
\hline
\end{tabular}




\begin{tabular}{|l|l|l|l|}
\hline pequena espécie & & $\begin{array}{l}\text { porcos da Índia alimentados } \\
\text { de plantas tradicionais, } \\
\text { algumas constituindo ervas } \\
\text { daninhas, crescendo nos } \\
\text { campos depois das colheitas }\end{array}$ & $\begin{array}{l}\text { recurso em espaços com elevada } \\
\text { densidade com déficit de } \\
\text { pastagens. São geralmente } \\
\text { resistentes a seca e polifágicas } \\
\text { (omnívoras). A seleção das espécies } \\
\text { também respeita aspectos religiosos }\end{array}$ \\
& $\begin{array}{l}\text { Variedades } \\
\text { melhoradas } \\
\text { hibridas em } \\
\text { aviários }\end{array}$ & $\begin{array}{l}\text { Variedades tradicionais. } \\
\text { Criação ao ar livre em } \\
\text { galinheiros. Uso de galinhas } \\
\text { para cerimónias tradicionais } \\
\text { com vista ao reforço de laços } \\
\text { familiares de amizade. Uso } \\
\text { para pagamentos em espécie. }\end{array}$ & $\begin{array}{l}\text { As galinhas possuem um valor } \\
\text { instrumental e simbólico } \\
\text { simultaneamente. } \\
\text { As raças, cores, contam nas } \\
\text { cerimonias mágico-religiosas }\end{array}$ \\
\hline
\end{tabular}

Adaptado de Scoones et all., 1996.

\section{CONSIDERAÇÕES FINAIS}

A ideia de que a globalização anulou tanto o espaço e o tempo, reduzindo a influência da geografia à semelhança do fim da história, é bastante ilusória. O paradigma da diversidade tenta revitalizar a tradição da geografia desde os seus primórdios de estudar lugares, evidenciando as suas diferenças e vantagens comparativas. Qualquer região, por reduzida que seja, é geodiversa. A geodiversidade pode ser vista a diferentes escalas do local ao global e juntamente com a biodiversidade e a sociodiversidade constitui o suporte da cooperação internacional, incentivando o crescimento sustentável e a convivência pacífica entre diversos povos. Vizinho não se escolhe, dizia Samora Machel, ao enfatizar a unidade na diferença e a coexistência pacífica em tempos de Guerra Fria.

Tão importante é o paradigma da diversidade no contexto atual de Moçambique, mas muito carece de mentes iluminadas que, olhando atentamente para a concretude da nossa realidade, possam imprimir nela aquela luz que permitir-nos-á ver a riqueza e profundidade dos conhecimentos que nela se escondem, desocultando o que até agora nos é oculto e fazendo do nosso moçambique geodiverso, biodiverso e sociodiverso a verdadeira base do nosso ensino e uma fonte de inspiração para as nossas pesquisas.

\section{NOTAS}

1 - Professor responsável pelo Colégio de Doutorado em Geografia da Universidade Pedagógica de Moçambique; professor no curso de graduação em geografia na mesma universidade na Delegação da Beira.

2 - Limpeza do roçado.

3 - A "roça" propriamente dita. A expressão também se associa ao lugar onde se pratica a agricultura da comunidade. 


\section{BIBLIOGRAFIA}

BREY, Laurent de, Conflito de Paradigmas, Habermas, Renaut: duas estratégias de renovação do projecto moderno. Instituto Piaget, Lisboa, 2009

BRILHA, José., Património Geológico e Geoconservação, A Conservação da Natureza na sua Vertente Geológica, Palimage, Lisboa 2005

ELLIS, Frank \& Allison, Edward, Livelihood diversification and Natural Resources, LSP Working Paper 9 , Roma, 2004.

FERRÃO, José, A convenção Sobre a Diversidade Biológica, Gestão Comunitária dos Recursos Naturais na África Austral, Texto Editores, Lisboa, 2010.

FORTUNA, Carlos; (Micro)territorialidade: metáfora dissidente do social, Coimbra, 2012 LEFF, Enrique; Saber Ambiental, sustentabilidade Racionalidade Complexidade Poder. Ed. Vozes, $3^{\mathrm{a}}$ ed. Petrópolis, 2004.

HAESBAERT, Rogerio., Territorios, In-segurança e risco em tempos de contenção territorial, in: Ferreira, $\mathrm{H}$ et all., A Experiencia Migrante: Entre Deslocamentos e Reconstruções. Rio de Janeiro: Garamond,2010, pp 537-557.

LEFF, Enrique; Saber Ambiental, sustentabilidade Racionalidade Complexidade Poder. Editora Vozes, $3^{\mathrm{a}}$ ed. Petrópolis, 2004

LOPES, José. Corredores Mineiro-Energéticos 2020 Impactos Marítimos do Afro-Índico no Canal de Moçambique, CESAB. Maputo. 2013

MELO, Alexandre. Globalização e Cultura, Quimera Editores, $1^{\text {a }}$ Ed. Lisboa, 2002

OMBE, Zacarias. Environmental Change in South Central Chibuto, Southern Mozambique, 1965-2000, Tese de Doutoramento,Universidade de Witwatersrand, RSA, 2006.

RODRIGUEZ, José Manuel et all. Geocologia das paisagens, uma visão geossistêmica da análise ambiental, UFC edições, $2^{\text {a }}$ ed. Fortaleza, 2007

SANTOS, Milton, A natureza do Espaço, Técnica e Tempo, Razão e Emoção, $3^{\text {a }}$ ed. São Paulo. 1999.

SCOONES et all. Hazards and Opportunities, farming livelihoods in dryland Africa, lessons from Zimbabwe, Zed Books, Ltd, London, pp: 1996,pp 243-246.

UAIENE, Rafael N. Estrutura, conduta e desempenho da agricultura familiar em Moçambique in Contributos para o debate da agricultura e desenvolvimento rural; Editora Escolar, Maputo, 201, pp 49-67

UNESCO. Década de Educação Nas Nações unidas Para o Desenvolvimento Sustentável, 2005-2014, documento final do esquema internacional de implementação, Brasília, 2005

WAMSLEY, D. Contemporary Social Change as the context for Geographical Enquiry: Towards a Reinvigoration of the concept of place, Geographical Research, 2012, pp: 50, 2,115-125 